\title{
Experimentalsysteme im Dispositiv der Biomacht
}

\section{Vom Öffnen der Black Box des Genome Editing mit CRISPR-Cas9}

\begin{abstract}
[...] so müsste man von ,Bio-Politik‘ sprechen, um den Eintritt des Lebens und seiner Mechanismen in den Bereich der bewussten Kalküle und die Verwandlung des Macht-Wissens in einen Transformationsagenten des menschlichen Lebens zu bezeichnen. ${ }^{1}$
\end{abstract}

We can now engineer the human race. ${ }^{2}$

Glaubt man dem Eingangszitat auf dem Cover der Mai/Juni-Ausgabe 2015 des MIT Technology Review, ${ }^{3}$ dann wurde die Menschheit Anfang 2013 durch die Entwicklung des Genome Editing unter Verwendung der sogenannten ,Genschere' CRISPR-Cas9 in die Lage versetzt, ihre eigenen genetischen Grundlagen zukünftig zielgenau biotechnologisch verändern zu können. Angesichts dessen ist unschwer zu erkennen, dass das Wissen der Molekularbiologie und die mit ihm verbundenen Artefakte und Techniken längst zu „Transformationsagenten des menschlichen Lebens“4 geworden sind. Das Genome Editing mit CRISPR-Cas9 reiht sich damit, wie etwa Eva Šlesingerová in einem aktuellen Beitrag gezeigt hat, nahtlos in eine lange Reihe von Elementen biopolitischer Dispositive ein, die auf die Regulierung, Kontrolle und Steigerung menschlicher (und nichtmenschlicher) Lebensprozesse abzielen. ${ }^{5}$

Dass molekularbiologische Artefakte wie CRISPR-Cas9 dazu in der Lage sind, derartige Machtwirkungen zu entfalten, erklärt jedoch noch nicht, wieso sie dazu in der Lage sind - und wie sie in diese Lage versetzt wurden. Angesichts der Offenheit und Unbestimmtheit von Forschungsprozessen und der Eigendynamik des Materiellen, auf die die mikrologischen Laborstudien der letzten Jahrzehnte immer wieder hingewiesen haben, ist genau diese Passförmigkeit der Objekte aber erklärungsbedürftig. Anhand der Genese von CRISPR-Cas9, von den ersten Spuren bis zum technischen Instrument des Genome Editing, wird im Folgenden gezeigt, wie das Zusammenspiel materieller, technischer und diskursiver Elemente in Experimentalsystemen ${ }^{6}$ molekularbiologische Objekte schrittweise zu Black Boxes ${ }^{7}$ werden lässt. Dabei wird

1 Foucault 1983 [1976], 138.

2 MIT Technology Review 118 (3), Hefttitel.

3 Vgl. Pontin 2015, 2, Editorial.

4 Foucault 1983 [1976], 138.

5 Šlesingerová 2019.

6 Rheinberger 1992; Rheinberger 2001.

7 Latour/Woolgar 1979; Latour 1987.

๖ Open Access. @ 2020 Philipp Zeltner, publiziert von De Gruyter. (G) BY-NC-ND Dieses Werk ist lizenziert unter der Creative Commons Attribution-NonCommercial-NoDerivatives 4.0 Lizenz.

https://doi.org/10.1515/9783110701319-010 
demonstriert, wie die aktuellen Bedingungen der Wissensproduktion in der Molekularbiologie so in die Formierung der Black Boxes hineinwirken, dass diese schließlich prädestiniert sind, sich in biopolitische Dispositive ${ }^{8}$ einzufügen.

Zunächst werden dazu CRISPR-Cas9 als Instrument des Genome Editing und die diese Technologie begleitenden Dynamiken kurz dargestellt. Im Anschluss daran wird der hier zugrunde gelegte Black Box(ing)-Begriff erläutert. Nachfolgend wird in einem ersten Analyseschritt der Genese von CRISPR-Cas9 im Rückgriff auf Hans-Jörg Rheinbergers Konzept der Experimentalsysteme die materiell-technische Bedingtheit und Eigenlogik der Konstitution molekularbiologischer Objekte herausgearbeitet. Im zweiten Schritt erfolgt dann mit Bezug auf metapherntheoretische Überlegungen eine Darstellung der produktiven Rolle der Metaphern molekularbiologischer Diskurse in der Genese von CRISPR-Cas9. Abschließend wird diese artefaktbiographische Rekonstruktion wieder auf die durch CRISPR-Cas9 in Bewegung geratenen Dispositive molekularer Biomacht rückbezogen.

\section{Genome Editing mit CRISPR-Cas9 - eine Technologie schlägt Wellen}

CRISPR-Cas9 - kein Akronym der Molekularbiologie hat es - seit RNA und DNA - zu mehr Berühmtheit gebracht als jenes, das für clustered regularly interspaced short palindromic repeats-CRISPR-associated sequence 9 steht. ${ }^{9}$ Es bezeichnet einen bakteriellen RNA-Proteinkomplex, der als System der Erkennung und des Abbaus von FremdDNA in der bakteriellen Immunabwehr eine Rolle spielt. Von den Arbeitsgruppen von Jennifer A. Doudna und Emmanuelle Charpentier wurde Ende 2012/Anfang 2013 sein möglicher Einsatz zu Zwecken des Genome Editing - also der gezielten Veränderung

\footnotetext{
8 Bereits an dieser Stelle sei darauf hingewiesen, dass das Foucaultsche Dispositiv eine Anordnung von Elementen meint, die als komplexes Ensemble Machtwirkungen zeitigen und Subjektivierungsprozesse strukturieren und strategische gesellschaftliche Funktion haben - etwa die angedeutete Steigerung menschlicher Lebensprozesse auf individueller und kollektiver Ebene -, ohne auf eine dahinterstehende Intentionalität reduziert werden zu können. Vgl. detailliert hierzu die Darstellungen bei Arnold und bei Maschewski/Nosthoff in diesem Band. Das Foucaultsche Dispositiv ist dabei nicht zu verwechseln mit dem Dispositivbegriff bei Derrida/Rheinberger (s. u.).

9 Zur Verwendung dieser Abkürzung im Text sei hier darauf hingewiesen, dass immer dann von CRISPR-Cas9 die Rede ist, wenn das vollständig beschriebene Artefakt gemeint ist, dass inzwischen als Instrument des Genome Editing eingesetzt wird (auch wenn dieses eigentlich als sgRNA-Cas9Komplex bezeichnet werden müsste; allerdings hat sich die Nomenklatur CRISPR-Cas9 durchgesetzt). An Stellen im Text, an denen die Rede von CRISPR ist, ist damit nur die DNA-Sequenz gemeint, nicht der RNA-Protein-Komplex. Wird im Text CRISPR-Cas genannt, dann meint dies die Klasse bakterieller CRISPR-Cas-Systeme, bei denen verschiedene Subtypen unterschieden werden; CRISPR-Cas9 gehört zu den Typ II-Systemen.
} 
von DNA-Sequenzen in menschlichen und nicht-menschlichen Zellen - demonstriert. ${ }^{10}$ Dabei macht man sich zunutze, dass der RNA-Anteil des Komplexes komplementäre DNA-Abschnitte erkennt und bindet. Darüber dirigiert die RNA das gebundene Protein Cas9 an bestimmte Stellen in der DNA. Cas9 ist eine Endonuklease, die DNA-Doppelstränge ,schneidet‘. Durch die experimentelle Veränderung des RNAAnteils lassen sich mit diesem System sequenzspezifische DNA-Doppelstrangbrüche erzeugen. Durch geschicktes Ausnutzen zelleigener DNA-Reparaturmechanismen lassen sich damit genetische Modifikationen exakt an der Stelle des Doppelstrangbruchs einfügen. ${ }^{11}$

Diese Form der gezielten Intervention in die DNA eröffnet völlig neue Möglichkeiten der Genmodifikation auch und gerade in vivo, also in lebenden Wesen. Denn klassische Formen genetischer Laborversuche, der Gentherapie sowie der Pflanzenund Tierzucht waren gezwungen, auf weitgehend unspezifische Verfahren der Genmodifikation zurückzugreifen. Gewünschte DNA-Sequenzen wurden unkontrolliert an nahezu beliebiger Stelle in das zu modifizierende Genom eingebaut oder Mutationen zufallsverteilt im Genom erzeugt - in der Hoffnung, dabei auch die gewünschte Mutation zu erhalten. Demgegenüber erlaubt der Einsatz des in den Massenmedien als ,Genschere‘ bekannt gewordenen CRISPR-Cas9 ungleich präziseren Zugriff auf die Erbanlagen. Zudem ist das System (auch aufgrund seines modularen Aufbaus) flexibel an verschiedenste Zielsetzungen adaptierbar, einfach zu handhaben und zu allem Überfluss auch noch preiswert. Angesichts dessen scheint es wenig verwunderlich, dass sich diese Technologie rasant in den verschiedensten Bereichen der Forschung und Technologieentwicklung verbreitet hat.

Zugleich avancierte die als Revolution ${ }^{12}$ der Biologie gefeierte Technologie mit ihrem Siegeszug auch zum privilegierten Gegenstand kontroverser ethischer Auseinandersetzungen, ökonomisch getriebener Patentstreitigkeiten und eines molekulargenetischen ,Wettrüstens` zwischen China und den USA. Seit 2013 schaffte es

10 Jinek et al. 2012. Nach diesem ersten ,proof of concept‘ durch Jinek et al. 2012 zeigen im Januar 2013 gleich fünf verschiedene Publikationen parallel, dass die Methode auch in Säugetierzellen einschließlich verschiedener humaner Zelltypen eingesetzt werden kann. Zu diesen Veröffentlichungen zählen neben einer Publikation der Arbeitsgruppe von Doudna selbst auch Publikationen der Gruppen von Feng Zhang und von George L. Church vom Broad Institute, einem kooperativen Unternehmen der Harvard University und des Massachusetts Institute of Technology (Jinek et al. 2013; Le Cong et al. 2013; Church/Esvelt/Mali 2013). Die UCLA Berkeley, an der die Arbeitsgruppe von Doudna angesiedelt ist, und das Broad Institute fechten nun seit Jahren auch einen Rechtsstreit darüber aus, wer welchen Beitrag zur Technologieentwicklung von CRISPR-Cas9 geleistet hat und damit entsprechende Patentrechte geltend machen kann (für einen Überblick über dessen Entwicklung siehe Sherkow 2015, 2017, 2018).

11 Gelungene populärwissenschaftliche Darstellungen des Mechanismus finden sich etwa bei Ledford 2015 oder ausführlich bei Kozubek 2016.

12 Als Beispiele dieser Rhetorik der Revolution und der Disruption siehe Barrangou 2014; Ledford 2015. 
CRISPR-Cas9 nicht nur auf die Titelseite fast aller molekularbiologischen Publikationsorgane von Rang und Namen, sondern es schlägt auch weit über den spezialwissenschaftlichen Diskurs hinaus hohe Wellen in der medialen Öffentlichkeit. ${ }^{13}$ In allen Artikeln wird die Technologie als bahnbrechend bezeichnet und ihre VorreiterInnen werden als PionierInnen gefeiert, was sich auch in diversen Preisverleihungen ${ }^{14}$ und Auszeichnungen niederschlägt.

Da zudem Bahn- und Dammbruch in der öffentlichen Wahrnehmung von Gentechnologien nahe beieinanderliegen, entsteht eine breite gesellschaftliche Debatte über Gefahren und Risiken der neuen Methode. Insbesondere ihr möglicher Einsatz in der Keimbahn des Menschen wird in bioethischen Fachpublikationen und in den Massenmedien kontrovers diskutiert. ${ }^{15}$ Und auch führende ForscherInnen fordern 40 Jahre nach der Asilomar Conference on Recombinant DNA des Jahres 1975 wieder ethische Selbstverständigungsprozesse, teils gar ein Moratorium der Forschungen. ${ }^{16}$

Das am 9. Februar 2016 veröffentlichte Worldwide Threat Assessment of the US Intelligence Community, der jährliche Bericht des Director of National Intelligence an den US-Senat, stuft Genome Editing-Methoden sogar als Massenvernichtungswaffe ein. ${ }^{17}$ Zeitgleich sorgt der erste klinische Testeinsatz von CRISPR-Cas9 am Menschen durchgeführt an der Sichuan University und am West China Hospital in Chengdu - für Aufsehen vor allem in westlichen Medien. ${ }^{18}$ Man spricht bereits von einem neuen ,Wettlauf ins All', oder in den Worten eines wissenschaftlichen Beraters des ersten US-basierten klinischen Tests von CRISPR-Cas9: „I think this is going to trigger ,Sputnik 2.0‘, a biomedical duel on progress between China and the United States “. ${ }^{19}$ Kaum zwei Jahre später verkündet der chinesische Forscher He Jiankui auf dem Second International Summit on Human Genome Editing vom 27.-29. November 2018 in Honkong die Geburt der ersten mithilfe von CRISPR-Cas9 ,editierten“ Menschen. ${ }^{20}$

13 Vgl. bspw. The Economist 2015; Park 2016; Nelson 2016.

14 So erhielten Jennifer A. Doudna und Emmanuelle Charpentier im Jahr 2015 den von Größen des Silicon Valley mit drei Millionen US-Dollar dotierten und medial aufwendig inszenierten Breakthrough Prize in Life Sciences (Breakthrough Prize 2014) und wurden in den zurückliegenden Jahren bereits mehrfach als Nobelpreis-Kandidatinnen gehandelt.

15 Vgl. z. B. die obenstehend zitierten Artikel für massenmediale Diskussionen. Stellvertretend für die deutschsprachige professionelle Bioethik siehe etwa Ranisch et al. 2018; Hardt 2019. Und auch der Deutsche Ethikrat hat sich auf seiner Jahrestagung 2018 und in einer darauf basierenden Stellungnahme mit Genome Editing auseinandergesetzt (Deutscher Ethikrat 2019).

16 Wade 2015.

17 Clapper 2016.

18 Siehe z. B. Cyranoski 2016.

19 Cyranoski 2016.

20 National Academies of Sciences, Engineering, and Medicine 2019. 


\section{Vom Versiegeln und Öffnen molekularbiologischer Black Boxes}

Um als (bio-)technologische Instrumente des Genome Editing herhalten zu können, ist jedoch Voraussetzung, dass solche Objekte wie CRISPR-Cas9 als Black Boxes funktionieren. Damit ist an dieser Stelle - anders als beispielsweise bei der in diesem Band ebenfalls thematisierten Apple Watch ${ }^{21}$ - nicht gemeint, dass molekularbiologische Objekte sich der Wahrnehmung potentieller NutzerInnen als ,schwarze Kästen' im buchstäblichen Sinne präsentieren müssten, deren innerer Aufbau dem Auge durch eine visuell undurchdringliche Barriere und womöglich sogar intentional entzogen wäre. Vielmehr ist die Black Box hier im Anschluss an Bruno Latour begriffen als jedes Objekt, das sich aufgrund stabiler Input-Output-Relationen in erwartbarer und damit unproblematischer Weise als stummer Vermittler in Praxisvollzüge einbetten lässt. ${ }^{22}$ Der Black Box-Begriff verweist hier nicht darauf, dass der Zugang zu internen Strukturen und Mechanismen molekularbiologischer Objekte blockiert wäre. Vielmehr thematisiert der Begriff, dass ein solcher Zugang vernachlässigbar ist, solange das Objekt im Rahmen seiner technischen Verwendung tut, was es soll.

Genau das ist im Zusammenhang mit wissenschaftlichen Objekten jedoch nicht einfach anzunehmen. Denn wissenschaftliche Objekte sind selbst nicht unmittelbar gegeben, sondern werden erst in materiell, technisch und diskursiv bedingten Experimentalprozessen sukzessive realisiert und damit materiell und semantisch fixiert. Erst im Zuge dieser Realisierung gewinnen sie eine Unabhängigkeit von den lokalen Bedingungen ihrer Genese. Eben diese Elimination der wissenschaftlichen Produktionsprozesse im Resultat beschreiben Woolgar und Latour: „The result of the construction of a fact is that it appears unconstructed by anyone [...]“.23 Dieser Vorgang der Entkontextualisierung wird von ihnen als ,activity of creating black boxes, of rendering items of knowledge distinct from the circumstances of their creation“, kurz, als Black-Boxing beschrieben. ${ }^{24}$

Erfolgreiche wissenschaftliche Konstruktionsprozesse in der Molekularbiologie darauf weist der hier verwendete Begriff der Black Box hin - erzeugen also unabhängige Entitäten genuin technischer Qualität, die sich als stumme Vermittler in Praxisvollzüge einfügen und diese dadurch strukturieren. Damit aber wird die historische Rekonstruktion der Genese molekularbiologischer Objekte - also die ,Öffnung einer solchen Black Box - notwendiger Bestandteil einer kritischen Reflexion der mit diesen verbundenen gesellschaftlichen Praktiken. Denn dadurch lassen sich die (materiellen, technischen, diskursiven, sozialen etc.) Bedingungen, die in die Prozesse

21 Vgl. den Beitrag von Maschewski/Nosthoff in diesem Band.

22 Latour 1998 [1994], 39.

23 Latour/Woolgar 1979, 240.

24 Latour/Woolgar 1979, 259. 
der Konstitution, der materiellen und diskursiven Verdichtung eines Objektes wie CRISPR-Cas9 hineinwirken, die im finalen Objekt aber unsichtbar geworden sind, herausarbeiten. Erst darüber wird verständlich, wie und wieso diese Objekte als Elemente von Dispositiven molekularer Biomacht operieren können.

\section{Von der Anomalie zur Waffe, von der Waffe zum Werkzeug - CRISPR-Forschung 1987-2012}

Diese historische Genese von CRISPR-Cas9 wird im Folgenden dargestellt. Dabei lassen sich grob zwei Phasen unterscheiden: Eine erste Phase der Stabilisation und Organisation, die in den 1980er Jahren beginnt und eine zweite Phase der Funktionalisierung und Instrumentalisierung. Der Übergang zu dieser zweiten Phase erfolgt in den Jahren 2003-2005. Die Darstellung der Genese erfolgt in Form von Schlaglichtern. Der analytische Fokus liegt dabei für die Phase der Stabilisation und Organisation auf den materiellen und technisch-apparativen Bedingungen. Gemeint sind damit an dieser Stelle konkrete, materiell und technisch vermittelte Praxisvollzüge im molekulargenetischen Labor, die an der Realisierung erster Spuren von CRISPR beteiligt sind. ${ }^{25}$ Diese werden im Rückgriff auf das Modell der Experimentalsysteme von Hans-Jörg Rheinberger in den Blick genommen. Anhand der ersten Spuren von CRISPR wird dabei die graphematische Grundstruktur der Materialität molekularbiologischer Objekte herausgearbeitet und ihr Charakter als „spurförmiges Dispositiv“ bestimmt. ${ }^{26}$

Die produktive Rolle molekularbiologischer Diskurse in der Formation der Objekte wird dann anhand eines zweiten Schlaglichts demonstriert. Der technisch vermittelte Übergang von der Erforschung der Struktur und Verbreitung von CRISPR hin zur Analyse seiner biologischen Funktion wird daraufhin untersucht, wie vor allem die in den Diskursen kursierende Metaphorik die Vorstellungsräume der Molekularbiologie und damit die Interpretation der materiell-technisch erzeugten Spurengefüge vorstrukturiert. Im Fokus stehen dabei die Kriegs- und Kampfmetaphern, die seit jeher die Bereiche der Immunbiologie und der Bakteriologie prägen und auch hier den interpretativen Rahmen bilden, der die semantische Fixierung der Funktion von CRISPR-Cas9 als einem ,Verteidigungssystem‘ im ,molekularen Wettrüsten“ von Bakterien und Bakteriophagen ${ }^{27}$ ermöglicht.

25 Nicht gefasst sind darunter beispielsweise ökonomische Bedingungen der Biowissenschaften, wie sie etwa unter dem Stichwort des Biokapitalismus diskutiert werden. Vgl. für einen diesbezüglichen Überblick Helmreich 2008.

26 Rheinberger 2001, 118.

27 Bakteriophagen - übersetzt ,Bakterienfresser` - sind bakterienbefallende Viren. 


\section{Die Phase der Stabilisation und Organisation - Stotternde Anfänge im Phosphatstoffwechsel-Experimentalsystem von Escherichia coli}

Nachfolgend wird - vor der eigentlichen Darstellung der ersten Phase der Stabilisierung von CRISPR-Cas9 - zunächst das zur historisch-genetischen Öffnung dieser Black Box verwendete Konzept der Experimentalsysteme von Hans Jörg Rheinberger vorgestellt. Ähnlich wie auch Latour interessiert sich Rheinberger dafür, wie und unter welchen Bedingungen in den Experimentalwissenschaften - allen voran der Molekularbiologie und Biochemie des 20. Jahrhunderts - neue Entitäten hervorgebracht werden. ${ }^{28}$ Deren Erkenntnisgegenstände sind für ihn nicht einfach als unabhängige, natürliche Entitäten von Beginn an im Verborgenen vorhanden; vielmehr gehen diese epistemischen Dinge selbst ,aus dem Bestand des Technischen hervor und aus den Basteleien, die dieses Arsenal möglich macht“. ${ }^{29}$ Im Gegensatz zur nach wie vor populären Vorstellung eines unidirektionalen Abhängigkeitsverhältnisses von Technik als angewandter Wissenschaft ist für ihn Wissenschaft also in ihrem Kern technisch verfasst. $^{30}$

Die basale funktionale Einheit von Forschungsprozessen bilden Experimentalsysteme, die er mit Francois Jacobals „Maschinen der Herstellung von Zukunft“ versteht. ${ }^{31}$ Dabei handelt es sich um „lokal begrenzte Gefüge, die aus architektonischen, technischen, sozialen, semiotischen und kognitiven Komponenten bestehen“".32 Anders als rein technische, auf Identität in der Ausführung zielende Konstruktionen operieren diese Experimentalsysteme über die Erzeugung unvorwegnehmbarer Differenzen. ${ }^{33}$ Als Gesamtensemble technisch vermittelter Praxisvollzüge bilden sie den Rahmen der Darstellung wissenschaftlicher Gegenstände, die als „Herstellung, eine[r] Produktion, in der das Dargestellte selbst überhaupt erst Gestalt annimmt“, verstanden

28 Rheinberger 1992, 2001, 2006; Müller-Wille/Rheinberger 2009b, 2009a. Ungeachtet vieler Übereinstimmungen mit und positiver Bezüge auf Latour, gibt es jedoch auch einige gewichtige Unterschiede, die ausschlaggebend für den hier erfolgenden Vorzug des Modells der Experimentalsysteme gegenüber der Akteur-Netzwerk-Theorie zur Öffnung der Black Box CRISPR-Cas9 sind. Dabei ist es insbesondere Latours methodische Vorliebe für die ethnographische Feldforschung, die sich als Problem darstellt. Denn diese Vorliebe geht bei Latour mit der Annahme einher, dass sich wissenschaftliche Black Boxes fast nur durch die Beobachtung ihrer Schließung in actu wieder öffnen lassen, also qua teilnehmender Beobachtung - oder alternativ durch den ,Glücksfall' einer späteren Kontroverse, die die Black Box zufällig destabilisiert. Demgegenüber favorisiert Rheinbergers historiographisches Modell die Rekonstruktion ex post auf Basis von Dokumenten- und Gesprächsanalysen. Damit eröffnet sie den Zugang zu bereits erfolgten Schließungsprozessen.

29 Rheinberger 2001, 153.

30 Rheinberger 2005, 104-128; 2006, 50-51.

31 Rheinberger 1992, 22; 2005, 25.

32 Schmidgen 2008,459; vgl. auch Rheinberger 1992, 21-46, 2001, 18-35.

33 Rheinberger 1992, 71-72. 
wird. ${ }^{34}$ Epistemische Objekte in wissenschaftlichen Praxisvollzügen sind daher zunächst unscharfe Objekte, die durch die technischen Randbedingungen des Experimentalsystems zugleich ermöglicht und beschränkt werden. Sie sind dadurch gekennzeichnet, dass sie sich erst im Prozess ihrer materiellen Definition befinden - sie sind zu Beginn nicht mehr als eine Serie materieller Spuren im Experimentalsystem.

\title{
CRISPR als materielles Spurengefüge - Auftritt einer „ungewöhnlichen Struktur“
}

Erste Spuren dessen, was später die erste CRISPR-Sequenz sein wird, konstituieren sich zwischen 1982 und 1987 in einem um den Modellorganismus Escherichia coli angeordneten Experimentalsystem in den Laboren der Arbeitsgruppe von Atsuo Nakata am Research Institute for Microbial Diseases der Universität Osaka in Japan. ${ }^{35}$ Eigentlicher Gegenstand der Forschungen war der Phosphatstoffwechsel des Bakteriums. Im Zuge dessen wurde ein 1,7 Kilobasen langes DNA-Fragment kloniert und sequenziert, welches das Gen eines am Stoffwechsel beteiligten Enzyms, genannt iap, enthalten sollte. ${ }^{36}$ Dabei gestaltete sich die Sequenzierung der Region am 3'-Ende des Fragments, also nach Lesekonvention von DNA-Sequenzen unterhalb bzw. downstream des vermuteten Gens, schwierig. Sie konnte erst nach mehreren Monaten experimenteller Arbeit realisiert werden. ${ }^{37}$ Erwähnt wird die Sequenz, die die Forscher dabei ,finden', interessanterweise nicht im Ergebnisteil der Publikation, sondern erst am Ende des Diskussionsabschnitts. Da sie für die anschließende Reflexion sehr aufschlussreich ist, soll sie hier vollständig und in Kombination mit der zugehörigen Abbildung (Abb.1) wiedergegeben werden:

\begin{abstract}
An unusual structure was found in the 3 '-end flanking region of iap (Fig.5). Five highly homologous sequences of 29 nucleotides were arranged as direct repeats with 32 nucleotides as spacing. The first sequence was included in the putative transcriptional termination site and had less homology than the others. Well-conserved nucleotide sequences containing a dyad symmetry, named REP sequences, have been found in E. coli and Salmonella typhimurium (28) and may act to stabilize mRNA (18). A dyad symmetry with 14 nucleotide pairs was also found in the middle of these sequences (underlining, Fig.5), but no homology was found between these sequences and the REP sequence. So far, no sequence homologous to these has been found elsewhere in procaryotes, and the biological significance of these sequences is not known. ${ }^{38}$
\end{abstract}

34 Rheinberger 1992, 73; Herv. i. O.; Rheinberger vertritt demnach weder eine klassische Abbildtheorie im Sinne einer Repräsentation ,von' etwas, noch treten Spuren epistemischer Dinge als Vertretung, als „Verdopplung einer Präsenz“ auf - weder die Kopie noch das Theater liefern ihm das Vorbild für die Wissensproduktion der Molekularbiologie (Rheinberger 2001, 110-111).

35 Nakata/Shinagawa/Amemura 1982; Ishino et al. 1987.

36 Dieses Enzym ist für die Konversion der verschiedenen Isozyme der alkalinen Phosphatase verantwortlich; von dieser Funktion leitet sich auch das Akronym iap ab (isozyme alkaline phosphatase). 37 Forterre/Ishino/Krupovic 2018, 3.

38 Ishino et al. 1987, 5432. 


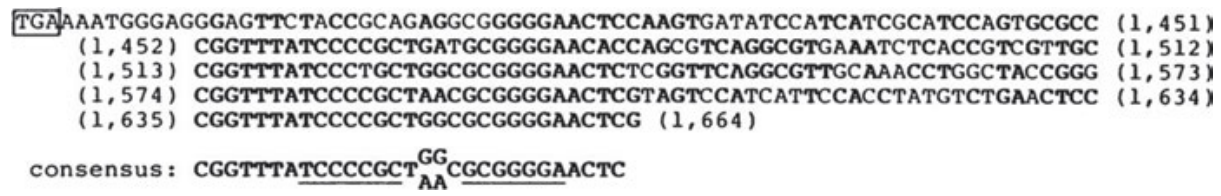

Abb. 1: Reorganisierte Darstellung der DNA-Sequenz der an das 3'-Ende des iap-Gens anschließenden Region. Übernommen aus Ishino et al. 1987: 5432.

Abgesehen von ihrer überraschenden Position innerhalb der Publikation - im Diskussionsabschnitt finden sich in der Regel vor allem Erklärungen/Interpretationen der zuvor dargestellten Resultate und spekulative Überschüsse, die über die als gesichert verstandenen Ergebnisse hinausreichen - fällt die zurückhaltende Beschreibung ins Auge. Die in einem kürzlich erschienenen Review als „Mysterious Repeated Sequence“ ${ }^{39}$ beschriebene, hier als „unusual“ eingeführte Struktur scheint sich wesentlich dadurch auszuzeichnen, dass sie sich einer Einordnung widersetzt. Der Versuch einer Interpretation durch den Vergleich mit anderen Sequenzen endet mit der schlichten Feststellung „no homology“. Stattdessen beschränkt sich die Darstellung darauf, die erzeugte Serie materieller Spuren noch einmal in natürliche Sprache zu übersetzen. Noch ist unklar, ob diese „ungewöhnliche Struktur“ von „biologischer Signifikanz" sein wird.

$\mathrm{Zu}$ Anfang seiner Historie ist also auch CRISPR nichts anderes als eine Serie materieller Spuren, die in wissenschaftlichen Praxisvollzügen erzeugt und verknüpft wurde. Diese Spuren können mit Rheinberger und in Anlehnung an Derridas Grammatologie auch als Grapheme verstanden werden, die immer zugleich als materiell, medial und semiotisch zu begreifen sind. ${ }^{40}$ Sie sind jedoch nicht einfache Spuren ,von etwas', das ihnen vorausginge, ein natürliches Objekt etwa, dem durch die Spur bloße Sichtbarkeit verliehen würde. Vielmehr sind die Objekte der Molekularbiologie von einer konstitutiven Nachträglichkeit geprägt. Denn erst die in technisch vermittelten Praktiken realisierte Spur „erzeugt, was man mit einer ebenso halluzinatorischen wie unausweichlichen Geste der Vergewisserung ihren Ursprung nennt.“411 Dabei verweist jede Spur auf die nächste, denn „,[w]issenschaftliche Repräsentationen können letztlich nur in Ketten

39 Forterre/Ishino/Krupovic 2018, 1.

40 Materiell sind Grapheme insofern, als sie Anordnungen sinnlich wahrnehmbarer Spuren sind; semiotisch deshalb, weil sie zugleich als materielle Zeichenträger, als Signifikanten funktionieren, die in ihrer Verkettung Sinn erzeugen; als medial lassen sie sich verstehen, da sie das Dritte darstellen, das zwischen der Ebene der Dinge und der Ebene der Wörter steht, das diese beiden verknüpft beziehungsweise diese in ihrer jeweiligen Abhängigkeit voneinander überhaupt erst hervorbringt. In dieser Perspektive sind also weder die wissenschaftlichen Theorien noch die Dinge Ausgangspunkt der Wissensproduktion, sondern die dazwischenliegenden, in experimentellen Praxisvollzügen erzeugten Grapheme.

41 Rheinberger 2005, 28. 
von Darstellungen Bedeutung erhalten“. ${ }^{42}$ Dass ein Graphem immer auf weitere Spuren insistiert und auch nur dadurch stabilisiert wird, führt Rheinberger dazu, epistemische Dinge auch als „spurförmige Dispositive“ zu bezeichnen; diese

funktionieren nach dem Prinzip des Graphismus - nach Derrida die Produktion einer Markierung oder eines Zeichens -, das eine Art ihrerseits nun produzierende Maschine konstituiert, die durch mein zukünftiges Verschwinden prinzipiell nicht daran gehindert wird, zu funktionieren und sich lesen und nachschreiben zu lassen ${ }^{6}{ }^{43}$

An diesem Punkt ist in der Rheinbergerschen Konzeption ein wesentlicher Aspekt der Eigendynamik des Materiellen verortet: Sie gründet im dispositionalen Charakter der Graphematizität epistemischer Dinge. Diese Eigendynamik zeigt sich auch im hier dargestellten Forschungsprozess an der gefundenen „ungewöhnlichen Struktur“, die rekursiv zur ersten Spur von CRISPR-Cas9 wird. Denn diese ist zwar einerseits noch vergleichsweise offen und unbestimmt - ein Element, dessen Auftreten nicht im Forschungsdesign angelegt war, das sich nicht verorten lässt und mehr Fragen als Antworten generiert. Andererseits ist das Spurengefüge jedoch schon so weit stabilisiert, dass es als Addendum eines anderweitig ausgerichteten Forschungsprozesses fixiert und publiziert werden kann. Diese kontrollierte Darstellbarkeit verleiht dem epistemischen Ding CRISPR partiell technischen Charakter; es beginnt, die weitere Ausrichtung des Experimentalsystems zu bestimmen und wird damit zu einem spurförmigen Dispositiv. Hier artikuliert sich der operative Charakter des Materiellen, seine aktive Beteiligung an der Ausrichtung des Experimentalsystems. Denn die 29 Basenpaare lange, repetitive Sequenz wird nun ihrerseits als radioaktiv markierte Sonde in weitere Forschungsprozesse an anderen Bakterien eingefügt, um hier weitere Serien von Spuren zu erzeugen und sich damit über eine Reihe verschiedener Spezies hinweg auszubreiten. ${ }^{44}$

\section{Trennen, Verketten, Stottern, Zersetzen - Kennzeichen experimenteller Praxis}

Bis zu diesem Zeitpunkt, an dem CRISPR seinerseits schon soweit stabilisiert ist, dass es selbst als spurförmiges Dispositiv erste signifikative Wirkungen entfaltet, ist jedoch schon jahrelange experimentelle Arbeit verrichtet worden - allein zwischen

42 Rheinberger 2001, 112. Es ist diese Verkettung der Darstellungen, die notwendig ein abbildtheoretisches Verständnis von Repräsentation konterkariert, da jeder materielle Signifikant immer nur auf den nächsten Signifikanten verweist. Diesbezüglich hebt er hervor: „Es gibt in der Wissenschaft nichts, was dieser permanenten Vorgängigkeit der Darstellung entginge, diesem ständigen Gleiten einer Repräsentation unter die andere, womit sie gleichzeitig ihren Sinn als Abbildung unterläuft“ (Rheinberger 2005, 23).

43 Rheinberger 2001, 118.

44 Amemura/Makino/Nakata 1989, 3553. 
Klonierung und Sequenzierung des DNA-Fragments mit der putativen Gensequenz von iap liegen fünf Jahre Forschungsprozess. Auf diese im Objekt verborgene Geschichtlichkeit, die sich als Serie schrittweise stabilisierter, technisch vermittelter Praktiken darstellt, soll im Folgenden eingegangen werden.

Bei genauerer Betrachtung dieser Praktiken fällt auf, dass in ihnen vor allem Trennungsarbeit verrichtet wird. Darunter sind hier alle Praktiken der Selektion, der Separation und Isolation gefasst, die materiale Fragmente graphematischer Disposition hervorbringen und verknüpfen. Dadurch wird schrittweise die opake Materialität einer E. coli-Kultur soweit aufgebrochen und in aufeinander verweisende Grapheme überführt, dass am Ende des Forschungsprozesses die obenstehende, als DNA-Sequenz begriffene Buchstabenfolge (Abb.1) als Teil eben jener anfänglichen Bakterienkultur erscheint. Gewährleistet wird dieser Verweisungszusammenhang, indem Elemente des jeweils bereits technisch stabilisierten Spurengefüges isoliert und in neue technische Arrangements eingefügt werden.

Eine solche Verkettung experimentell zu erzeugen ist jedoch keineswegs ein problemloses technisches Prozessieren des jeweiligen Ausgangsmaterials. Vielmehr gerät dieser Prozess beispielsweise bei der oben angesprochenen Sequenzierung der 3‘-Region des untersuchten DNA-Fragments über mehrere Monate hinweg ins ,Stottern“. An dieser Stelle artikuliert sich die Materialität der Objekte nicht durch ihre Operativität, sondern über ihre Widerständigkeit. Reagiert wird darauf zunächst durch Verschiebung der technischen Randbedingungen, das sogenannte trouble shooting; scheitert auch dieses, so werden etwa durch Literaturkonsultation alternative Varianten der technischen Erzeugung von Spuren gesucht; die Widerständigkeit des Materiellen in den Praxisvollzügen zwingt also zur Reflexion eben dieser Vollzüge. ${ }^{45}$

\section{CRISPR-Sequenzen als Technophänomen und DNA-Sequenzierung als Phänomenotechnik}

Das epistemische Objekt, dass sich rekursiv als CRISPR-Sequenz darstellt, ist also dadurch gekennzeichnet, dass es sich vermittels experimenteller Arbeit an widerständiger Materialität als graphematisches Spurengefüge konstituiert. Neben dieser Materialität ist es nun die fundamentale Technizität dieses molekulargenetischen Objekts, die Beachtung verdient. Auf diese grundlegende Rolle der Technik verweist,

45 Greift im Übrigen auch diese Form der Reflexion der Praxis nicht, dann bewegt sich der Forschungsprozess zeitlich rückläufig entlang der signifikanten Kette und destabilisiert die bereits erzeugten Spuren. Diese rekurrente Bewegung ist spiegelbildlicher Effekt der Graphematizität, da sich graphematische Spuren ja nur durch den Verweis auf den nächsten materiellen Signifikanten stabilisieren lassen. Kann dieser nicht realisiert werden, destabilisiert dieses ,Stottern“ die bisherigen graphematischen Gefüge des Experimentalsystems; die Verpflichtung auf die Zukunft zersetzt rekursiv die Vergangenheit. 
wie bereits kurz angerissen, das Modell der Experimentalsysteme. Denn epistemische Dinge stellen nur eine der beiden formal bestimmbaren Komponenten der Experimentalsysteme dar, die an dessen zweite Komponente strukturell gekoppelt und irreduzibel mit dieser verbunden sind. Diese zweite Komponente bilden die technischen Dinge, die als stabile und stabilisierende Randbedingungen der ersteren auftreten. ${ }^{46}$ Diesbezüglich vertritt Rheinberger eine weiche (und weite) Definition von Technik, er möchte sie nicht auf die konkreten Instrumente und Apparate im Labor und damit auf ein an der Mechanik orientiertes Technikverständnis verkürzt wissen. ${ }^{47}$ Vielmehr können all jene Praxisvollzüge einschließlich ihrer materiellen, semiotischen, sozialen und kognitiven Komponenten als technische Dinge begriffen werden, die sich in der wissenschaftshistorischen Rekonstruktion als an der Konstitution und Stabilisierung epistemischer Dinge beteiligt erweisen. ${ }^{48}$

Der Charakter solcher technischen Dinge wird nun anhand der DNA-Sequenzierung, die zu den ersten CRISPR-Sequenzen führt, dargestellt. Bei dieser Methode wird ein DNA-Fragment mit Nukleotiden, einem kurzen DNA-Abschnitt, dem sogenannten Primer, und dem Enzym Polymerase umgesetzt, wobei zu jedem der vier Reaktionsansätze je eines der vier Nukleotide im Unterschuss auch als Didesoxynukleotid zugegeben wird. Dadurch bricht die Polymerisierung der komplementären DNA-Fragmente statistisch verteilt jeweils an den Positionen ab, an denen ein solches Didesoxynukleotid in die wachsende DNA-Kette eingebaut wird. Diese vier Reaktionsansätze werden anschließend parallel auf ein Agarosegel aufgetragen und elektrophoretisch aufgetrennt. Da zudem einige Nukleotide radioaktiv markiert, also so modifiziert sind, dass sie auf einer Photoplatte eine Spur erzeugen, kann die Auftrennung anschließend als Bandenmuster sichtbar gemacht werden. ${ }^{49}$ In Flussrichtung der Elektrophorese ,gelesen' ergibt sich daraus die Basenfolge des in die Reaktion gegebenen DNA-Fragments. Die Anordnung führt also zur ,Übersetzung‘ des Prozessmaterials in ein graphematisches Spurengefüge - in diesem Fall in eine Serie von Banden auf einem Gel. Dieses

46 Rheinberger 2001, 25.

47 Rheinberger 1992, 69.

48 Vgl. dazu auch Schmidgen 2008, 459. Diese funktionale und nicht substanzielle Definition technischer Dinge schließt, wie anhand des Begriffs des spurförmigen Dispositivs gezeigt wurde, bei ausreichender Stabilisierung auch epistemische Dinge selbst mit ein (Rheinberger 1992, 70).

49 Diese Darstellung der Sequenzierung bezieht sich auf das Verfahren, wie es in den hier dargestellten Forschungsprozessen zum Einsatz kam. Seit den 1980er Jahren hat das Verfahren der Sequenzierung nach Sanger selbstverständlich eine Reihe von Veränderungen und Vereinfachungen erfahren. So werden mittlerweile keine radioaktiv markierten Nukleotide mehr verwendet, die Spuren werden vielmehr durch Fluoreszenzmarkierung der Nukleotide erzeugt. Außerdem werden in der Regel auch keine Sequenziergele mehr verwendet, sondern die Banden mittels Kapillarelektrophorese aufgetrennt und die Absorptionsmuster direkt technisch ausgelesen und in den Computer eingespeist. Auch wenn dabei die Spurenerzeugung technisch anders realisiert wird und einige Notationswechsel hinter dem Interface des Computers verschwinden, ändert all dies aber nichts am grundlegenden Prinzip der technisch vermittelten Spurenerzeugung in der DNA-Sequenzierung. 
Muster kann dann wiederum in die Abbildung einer Basenabfolge in Form der Buchstaben A, T, G und C ,übersetzt' werden. Letzten Endes führt diese Apparatur also zur Übersetzung des eingegangenen Prozessmaterials in eine Serie von Aussagen.

Eine solche technische Anordnung zeichnet sich dadurch aus, dass sie Identität herstellt, sie reproduziert gleiches. Allerdings ist diese Identitätsfunktion nicht so stark ausgeprägt, dass sie das Objekt vollständig determiniert; vielmehr ermöglicht und beschränkt es eine spezifische Repräsentationsweise - hier die Festlegung der Erscheinungsform auf ein Bandenmuster in einem Agarosegel - es bestimmt aber nicht die genaue Abfolge der Banden. Es erlaubt also nicht nur die „nicht-technische, ,gebastelte“ Anordnung von technologischen Dingen [...] die Emergenz von Wissenschaftsobjekten“.50 Schon innerhalb der einzelnen technischen Apparatur erfolgt keine exakte Festlegung - andernfalls handelte es sich nicht mehr um eine Forschungsanordnung, sondern ein rein technisches Ensemble. ${ }^{51}$ Die Beschränkung der Repräsentationsweise des epistemischen Dings CRISPR in Form eines Bandenmusters und einer niedergeschriebenen Basenfolge ist jedoch charakteristisch für das, was sich mit Gaston Bachelard als „Phänomenotechnik“ bezeichnen lässt. Für Bachelard stellen wissenschaftliche Apparate „materialisierte Theorien“ dar. ${ }^{52}$ In ihnen ist der jeweilige wissenschaftliche Wissenstand in materialisierter Form präsent, sie sind materielle Extensionen wissenschaftlicher Diskurse. ${ }^{53}$

Die Praxisvollzüge bei der Durchführung der DNA-Sequenzierung können damit allesamt als gewissermaßen ,materialisierte Aussagen verstanden werden. Beispielsweise kann die Zugabe der Nukleotide Adenosin, Thymidin, Guanosin und Cytidin zum Reaktionsansatz als materialisierte Form der Aussage angesehen werden, dass die DNA aus diesen vier Nukleotiden aufgebaut ist. Diese Präsenz materialisierter Aussagenfolgen in der Phänomenotechnik sorgt dafür, dass die Übersetzung der materiellen Spurengefüge in weitere Aussagen des wissenschaftlichen Diskurses gewährleistet ist. Die so ermöglichte Übersetzung zweiter Ordnung - vom Prozessmaterial über die graphematische Disposition des Materiellen zur Aussage - ist elementar für den Eintritt von CRISPR in den Raum des wissenschaftlichen Primärdiskurses. Und sie ist gleichzeitig Voraussetzung weiterer Forschungsprozesse, da sie in der diskret artikulierten Form einer Serie von Buchstaben in Datenbanken eingepflegt und mit anderen Sequenzen verglichen werden kann, weil sie ihrerseits als

\footnotetext{
50 Rheinberger 1992, 72.
}

51 Es ist sogar davon auszugehen, dass selbst in einem technischen Apparat, der vollständig auf die Erzeugung von Identität ausgerichtet ist, die Erzeugung von Differenz auftritt - auch, wenn die Identitätsfunktion dies verhindern soll. Dies gründet unter anderem darin, dass diese Funktion normativen und nicht faktiven Charakter hat, also als regulierende Norm in der Herstellung operiert. Dazu kommt, dass die Verwendung eines technischen Apparates niemals vollständig in seiner materiellen Anordnung festgelegt sein kann - es braucht immer auch diskursiv festgelegte Anwendungsregeln, und diese können sich gegenüber der Identitätsfunktion verschieben.

52 Bachelard 1988 [1934], 18; vgl. auch Rheinberger 1992, 22.

53 Sommer/Müller-Wille/Reinhardt 2017, 37. 
Synthesevorschrift für fluoreszenzmarkierte Sonden ${ }^{54}$ fungiert - sprich, weil sie in dieser graphematischen Disposition weitere Forschungen ausrichtet.

Zusammenfassend lässt sich für diesen Raum der Sichtbarkeiten, in dem CRISPR entsteht, feststellen: CRISPR konstituiert sich zunächst als unscharfes Objekt; es manifestiert sich als eine Serie materieller Spuren graphematischer Struktur, nachdem es sich zuvor als widerständiges Element in der experimentellen Arbeit artikuliert, dass den Forschungsprozess stocken lässt; diese Sequenzanomalie, aufgetreten in einem Forschungsprozess zum Phosphatstoffwechsel von Escherichia coli, ist ein in technisch vermittelten Praxisvollzügen realisiertes Phänomen. Seine phänomenotechnische Stabilisierung und Übersetzung in wissenschaftliche Diskurse erlaubt den Übergang vom epistemischen zum (partial) technischen Ding - dem spurförmigen Dispositiv.

\section{Von der Organisation zur Funktion - oder wie der Irakkrieg digitale Experimentalsysteme schuf}

Die bereits angedeutete Orientierung weiterer Forschungsprozesse durch dieses spurbzw. inzwischen auch textförmige Dispositiv führt zunächst - unter Verwendung der entsprechenden fluoreszensmarkierten Sonden - zur Beschreibung solcher DNA-Abschnitte auch in anderen E. coli-Stämmen und weiteren Bakterienarten durch die gleiche japanische Arbeitsgruppe. ${ }^{55}$ Wenig später identifiziert Francisco Mojica an der Universidad de Alicante bei halophilen, also ,salzliebenden', Archaeenarten ähnliche von sogenannten ,Spacern' unterbrochene, palindromische DNA-Abschnitte, gleiches demonstrieren ForscherInnen um Jan van Embden am niederländischen National Institute of Public Health and Environmental Protection beim Erreger der Tuberkulose, Mycobacterium tuberculosis. ${ }^{56}$ Beide Gruppen einigen sich mit dem Akronym CRISPR auf eine einheitliche Terminologie dieser DNA-Bereiche. ${ }^{57}$ Die Verbindung zwischen den verschiedenen Experimentalsystemen wird dabei nicht mehr auf der materielltechnischen Ebene realisiert, sondern auf der Ebene des Textes - genauer durch Datenbanken in zunächst analoger, später digitaler Form. ${ }^{58}$ Diese Datenbankannotation von Sequenzen stellt dabei selbst ein zunehmend produktives epistemisches Instrument dar. Weit davon entfernt, ein passives Ablagesystem für Buchstabenfolgen zu sein, entfaltet es eigene epistemische Wirkungen. Denn die Datenbanken resultieren

54 So zum Einsatz gebracht bei Amemura/Makino/Nakata 1989.

55 Amemura/Makino/Nakata 1989.

56 Juez/Mojica/Rodriguez-Valera 1993; Groenen et al. 1993; Mojica et al. 1995.

57 Die erste offizielle Erwähnung im Rahmen einer Publikation findet sich bei Jansen et al. 2002.

58 Darüber hinaus stiften die Datenbanken auch persönliche Beziehungen zwischen den beteiligten Labors, da die wenigen, weltweit verstreuten frühen CRISPR-ForscherInnen unter anderem über diese Datenbanken überhaupt erst wechselseitig voneinander Notiz nehmen. 
in der Akkumulation immer weiterer CRISPR-Sequenzen. Je dichter dieses Netz von CRISPR-Sequenzen sich über die analysierten Bakteriengenome verteilt, umso stärker insistiert diese Kette von Spuren auf ihre eigene Relevanz - eine biologische Funktion.

Neben diesem ,Insistieren auf eine Funktion' wird es durch diese Sammlungen auch möglich, die Ähnlichkeiten und Unterschiede der Sequenzen zu taxonomischen Zwecken zu nutzen. ${ }^{59}$ Diese taxonomischen Zwecke gehen dabei weit über wissenschaftliche Erkenntnisinteressen hinaus. Tatsächlich wird nämlich ein Teil dieser Arbeiten in den 1990er und den beginnenden 2000er Jahren vom französischen Verteidigungsministerium finanziert. Ziel der Forschungen war die Nutzung repetitiver Sequenzen in der DNA von pathogenen Bakterien wie Yersinia pestis zur Aufklärung von deren Herkunft, da Geheimdienstberichte Hinweise darauf geliefert hatten, dass der Irak unter Saddam Hussein über biologische Massenvernichtungswaffen verfügen könnte. ${ }^{60}$ Sollten Erreger als Waffe eingesetzt werden, wäre es anhand der angelegten Datenbanken möglich, so die Hoffnung, im Nachhinein nachweisen zu können, wer diese Erreger zum Einsatz gebracht hatte. ${ }^{61}$

Hier betritt zum ersten Mal der Krieg die Bühne, auf der CRISPR sich konstituiert. Dieser Umstand macht deutlich, dass es mehr benötigt als die Produktion signifikanter Differenzen, um Experimentalsysteme zu stabilisieren. Was Latour in seinen frühen Studien zu Pasteur ${ }^{62}$ gezeigt hat und zu einer Art Mantra der Akteur-NetzwerkTheorie geworden ist: Um wissenschaftliche Ergebnisse erzeugen und stabilisieren zu können, ist es immer notwendig, eine Vielzahl heterogener Akteure zu überzeugen und für die eigenen Zwecke zu mobilisieren - in diesem Fall unter anderem das Verteidigungsministerium. Will man einen Weg finden, auf die Bedrohung durch (vermutete) Massenvernichtungswaffen des Irak zu reagieren, dann führt dieser Weg durch die Labors der CRISPR-Forschung. Die Angst vor Saddam Hussein und seinen Mikroben wird zu einem vor allem finanziell stabilisierenden Faktor der CRISPR-Experimentalsysteme. Auf den epistemischen Kern der molekularbiologischen Wissensproduktion scheint sich der Krieg jedoch noch nicht auszuwirken. Dies ändert sich mit dem Eintritt in die zweite Phase der Genese von CRISPR - die Phase der Funktionalisierung und Instrumentalisierung. Dieser wird sich im Folgenden und im Rückgriff auf metapherntheoretische Perspektiven der neueren Wissenschaftsgeschichte zugewandt.

59 Goyal et al. 1997.

60 Kozubek 2016, 12.

61 Kozubek 2016, 13; vgl. auch Pourcel/Salvignol/Vergnaud 2005.

62 Latour 1988. 


\section{Die Phase der Funktionalisierung und Instrumentalisierung - Auf den Kriegsschauplätzen der Molekularbiologie}

Schon in der vorangegangenen Darstellung fiel mehrfach der Begriff des Diskurses. Dieser sprachlich verfasste Raum, in den die materiellen Spurengefüge in Form von Tabellen, Abbildungen, Diagrammen - also in Aussagenform - eingehen, ist zwar mit den materiellen und technischen Aspekten der Wissensproduktion aufs Engste verwoben. Doch ebenso, wie die Eigendynamik des Materiellen - ihre Widerständigkeit und Operativität - sich nicht auf einen bloßen Diskurseffekt, ein Sprachspiel reduzieren lässt, darf auch die Betonung des Materiellen in umgekehrter Richtung nicht dazu führen, das Diskursive als bloßes Epiphänomen zu betrachten. Auf beiden Seiten besteht die Möglichkeit von Überschüssen, Unbestimmtheiten und Eigendynamiken. Daher gilt es, die strukturierende Wirkung wissenschaftlicher Diskurse als Bestandteil der technischen Dinge ebenfalls einzubeziehen.

Dabei sind es gerade die in den biowissenschaftlichen Disziplinen kursierenden Metaphern, die einschränken und strukturieren, als was molekularbiologische Gegenstände erscheinen. ${ }^{63}$ Auf diesen Umstand hat auch Philipp Sarasin in explizitem Anschluss an Rheinberger hingewiesen:

Die im Labor generierten Signifikantenketten sind prinzipiell offen - nicht nur für das Auftauchen jener Differenz, die das Neue indiziert, sondern auch für Signifikanten, die von ,außen kommen beziehungsweise als Verunreinigung die Hypothesenbildung immer schon begleiten. ${ }^{64}$

Die wirklichkeitskonstitutive Kraft der Metaphern soll anhand der Folgen einer zentralen technisch bedingten Verschiebung in der historischen Genese von CRISPR-Cas9 verdeutlicht werden. Diese Verschiebung stellt den Auftakt der zweiten Phase der Entwicklung von CRISPR-Cas9 dar - der Phase der Funktionalisierung. Sie beginnt im Sommer 2003 in den Laboren von Alicante, dessen Ereignisse Francisco Mojica in einem Interview folgendermaßen beschrieb:

We had got some sequences from E. coli strains, we were sequencing the CRISPR loci to evaluate whether they could be used for genetic markers. We got a few of these sequences, and as I often did, I BLASTed these sequences against the database. For the first time, it matched a viral sequence. I thought maybe it is a coincidence, but it was not. ${ }^{65}$

63 Die Untersuchung der Metaphern biowissenschaftlicher Diskurse hat in der Wissenschaftsgeschichte und -soziologie einige Aufmerksamkeit erhalten - von historischen Studien zur Bakteriologie (Sarasin et al. 2007) und der Genese des, genetischen Codes' (Kay 2005) über Arbeiten zur Immunbiologie (Haraway 1991) bis hin zu Analysen des metaphorischen Verhältnisses von Biologie und Gesellschaft insgesamt (Maasen/Mendelsohn/Weingart 1995).

64 Sarasin 2003, 215.

65 Davies/Mojica 2018, 31. 
Diese computergestützte Datenbankrecherche stellt sich zunächst als technisch vermittelte Erzeugung einer neuen Spur, einer neuen Inskription dar. Ihr Effekt auf das gesamte Spuren- und Aussagengefüge von CRISPR ist jedoch immens. Denn was die Knüpfung dieser einen Verbindung, diejenige zwischen der DNA-Sequenz eines Spacers und der DNA-Sequenz eines Bakteriophagen als Konsequenz hat, lässt sich als fundamentale materielle wie semiotische Transformation, als ,epistemischer Sprung begreifen. Die gestiftete Beziehung zwischen einem Bakterium und seinem Virus, die sich durch die Datenbanksuche realisiert, überführt das gesamte Ensemble unwiederbringlich in einen neuen Diskursraum, voller neuer Metaphern, die die Imaginationen organisieren.

Denn zwischen 1987 und 2003 zirkuliert CRISPR im Diskursraum als Serie repetitiver DNA-Sequenzen, die durch DNA-Sequenzierung erzeugt und positioniert und dann manuell - später auch digital - in Beziehung gesetzt werden. Die dominanten Techniken der Experimentalsysteme sind die Sequenzierung und die Datenbank - und die zirkulierenden Metaphern stammen nahezu alle aus dem Bereich der Schrift. ${ }^{66}$

Mit der Datenbankrecherche von Mojica werden die Objekte nun einer materielldiskursiven Transformation unterworfen. Über die gestiftete Beziehung BakteriumBakteriophage rückt CRISPR plötzlich ein in einen Metaphernraum des Krieges und der Schlacht. Diese Charakterisierung mag überzogen und plakativ klingen. Sie hat allerdings in Bakteriologie und Immunbiologie eine lange Tradition. So hat beispielsweise Christoph Gradmann darauf hingewiesen, dass schon die Semantik der medizinischen Bakteriologie im deutschen Kaiserreich von der Einführung eines Antagonismus von Freund und Feind lebte - einschließlich der Metaphern einer „totalen Mobilmachung des Körpers“ und der „Wehrmacht der Leukozyten“. ${ }^{67}$ Kritik daran, dass „primitive Kampfmetaphern die ganze Immunitätswissenschaft durchtränken“ findet sich auch schon bei Ludwik Fleck, der bereits 1935 darauf hinweist, dass es „keinen einzigen experimentellen Hinweis gibt, der imstande wäre, einen Unvoreingenommenen zu solcher Auffassung zu zwingen“. ${ }^{68}$ Trotzdem ist diese militärische Metaphorik nach wie vor präsent, auch wenn sich die Bilder des Krieges zeitgemäß gewandelt haben. Dies wird beispielsweise in den Analysen von Donna Haraway sichtbar, die enge Parallelen zwischen Darstellungen des Immunsystems in den 1980er Jahren und kontemporären militärisch-kybernetischen Kontrollphantasien der Command-Communication-Control-Intelligence herausgearbeitet hat. ${ }^{69}$

66 Vgl. zu dieser ubiquitären Verwendung von Schrift- und Textmetaphern in molekularbiologischen bzw. -genetischen Diskursen und deren theoriekonstitutiver und damit produktiver Funktion die Analysen von Brandt 2004 und Kay 2005.

67 Gradmann 2007, 342-343.

68 Fleck 1993 [1935], 79.

69 Haraway 1991, 150; 203-230. 
Dieser hochtechnisierte, auf Informationskontrolle, selektiver Zielerkennung und -zerstörung basierende Kriegsschauplatz gibt nun auch den Diskursraum ab, in den CRISPR durch den Treffer in der Datenbank eintritt. Schon ein Blick in das Inhaltsverzeichnis von A Crack in Creation, einer populärwissenschaftlichen Darstellung der CRISPR-Forschung mit biographischer Schlagseite macht dies mehr als deutlich. Drei der ersten vier Kapitel tragen Titel wie „A New Defense“, „Cracking the Code“ und „Command and Control“ “. ${ }^{70}$ Es ist hier jedoch nicht der ,Krieg` zwischen Bakterien und Eukaryoten, der den diskursiven Horizont der Funktionsanalysen von CRISPR bildet, sondern derjenige zwischen Bakterien und Bakteriophagen. Die Darstellung dieser Beziehungen ist gespickt mit kriegerischen Metaphern: So sind die Phagen „lethal by design“, der bedrohlichste unter ihnen sieht aus wie ein „alien spacecraft“, ihr „genetic material explodes into the cell as soon as the protein shell is breached“, das Phagengenom „hijacks the host“ und Bakteriophagen „are waiting for the right moment to strike" etc. ${ }^{71}$

Nun mag man dies noch für einen illustrativen Gebrauch von Metaphern in einer populärwissenschaftlichen Publikation halten, der dazu dient, einem nicht-wissenschaftlichen Publikum die fremde Welt der Bakterien und Bakteriophagen nahezubringen, indem auf popkulturell bekannte Szenarien zwischen Kriegs- und Alienfilm rekurriert wird. Ähnliches gilt wohl auch für die inzwischen weitverbreitete Metapher der ,Genschere‘, die sicherlich auch eher dazu dient, die bizarre und bedrohlich anmutende Welt der molekularbiologischen Hochtechnologien an den ungleich vertrauteren Kontext der heimischen Bastelstunde anzuschließen, als tatsächlich die imaginären Räume der CRISPR-Forschungen zu organisieren. Die militärische Metaphorik geht jedoch über diese illustrative Funktion hinaus - sie hat im Zusammenhang mit CRISPR theorie- und objektkonstitutive Relevanz. ${ }^{72}$ Diese konstitutive Funktion zeigt sich einerseits daran, dass bei Abzug solcher Metaphern schlicht die Sprache für den korrespondierenden Objektbereich fehlt. Die Theorie oder der wissenschaftliche Gegenstand ist also entweder mit den Metaphern zu beschreiben - oder gar nicht. Zum Zweiten zeigt sich die konstitutive Funktion in der Produktivität der Metaphern, indem sie nämlich neue Gegenstandsbereiche zu erschließen erlauben. ${ }^{73}$

Beides zeigt sich für die Phase der Funktionalisierung von CRISPR-Cas9. Denn CRISPR und die benachbarten cas-Gene erhalten innerhalb dieses Diskurses, von diesem ,Kriegsschauplatz‘ der Bakterien und Bakteriophagen ihre sukzessive Funktionsbestimmung, die sich 16 Jahre lang dem experimentalwissenschaftlichen Zugriff

70 Doudna/Sternberg 2017.

71 Alle Zitate in Doudna/Sternberg 2017, 48-49.

72 Vgl. zur Unterscheidung der verschiedenen Funktionen bzw. Typen von Metaphern sowie darüber hinaus als allgemeine Einführung in neuere Positionen der Metapherntheorie die Ausführungen bei Brandt (2004, 28-54).

73 Vgl. Brandt 2004, 42-44. 
entzogen hat. CRISPR-Cas wird zu einem bakteriellen „defense system“, ${ }^{74}$ einer bakteriellen ,Waffe‘ gegen die allgegenwärtige Bedrohung der Phageninvasion. Die ab 2003 erfolgte Identifikation der Spacer-Sequenzen mit DNA aus Bakteriophagen bildet den Ausgangspunkt der Reorientierung der CRISPR-Forschungen. Sie widmet sich von nun an der Analyse der Komponenten des neuen bakteriellen ,Abwehrsystems'. Im Zuge dessen werden die in der genomischen DNA der Bakterien kodierten Protospacer-Sequenzen zu Erinnerungsmodulen vergangener Phageninvasionen. Sie bilden, in Verbindung mit den angrenzenden CRISPR-Sequenzen transkribiert und in reife CRISPR-RNA (eine sogenannte crRNA) prozessiert, die sogenannte guide-RNA, die die targets des CRISPR-Cas-Systems erkennt. ${ }^{75}$ In Verbindung mit den zwei anderen Komponenten eines CRISPR-Cas-Systems vom Typ II - der ebenfalls benachbart zu den CRISPR-Sequenzen kodierten tracrRNA und der Endonuklease Cas9 finden und zerstören sie fremde DNA, ein Mechanismus, der auch als seek and destroy beschrieben wird. ${ }^{76}$

Nach dem epistemischen Sprung bewegt sich CRISPR-Cas9 also in einem Diskursraum, der von einer politisch-militärischen Semantik des fortlaufenden molekularen Wettrüstens zwischen Bakterien und Bakteriophagen durchdrungen ist. Vor dem Hintergrund dieser Metaphorik erhalten CRISPR-Cas-Systeme ihre biologische Funktion, sie werden schrittweise zu einem Teil des adaptiven bakteriellen Immunsystems, einem antiviralen Verteidigungsmechanismus. Genauere Einsichten in diesen Mechanismus liefern Experimente von John van der Oost und Eugene Koonin in den Niederlanden, die ein künstliches CRISPR-Cas-System hergestellt und in einen CRISPR-losen Bakterienstamm eingebracht haben. ${ }^{77}$ Durch diese Experimente können sie die Minimalzusammensetzung eines solchen Virus-Resistenz verleihenden Systems rekonstruieren. Es stellt sich heraus, dass der Komplex aus Cas-Proteinen eine gebildete Vorläufer-RNA - bestehend aus der Serie von CRISPR und Spacern in aus je einem Spacer und dem angrenzenden CRISPR-Abschnitt bestehende, reife CRISPR-RNA spaltet. Diese reife CRISPR-RNA fungiert als guide-RNA, die die im cas9-Gen kodierte Endonuklease an die der Spacer-Sequenz komplementären Stellen in der DNA des Phagen dirigiert. ${ }^{78}$ Ende 2012 demonstrieren die Arbeitsgruppen von Jennifer A. Doudna von der University of California in Berkeley und Emmanuelle Charpentier von der umeå universitet in Schweden im Wissenschaftsmagazin Science dann die Verwendung von CRISPR-Cas9 zu Zwecken des Genome Editing. ${ }^{79}$

74 Mojica et al. 2009, 733.

75 Mojica et al. 2009.

76 Vgl. z. B. das Titelbild von Nature 507 (7490), März 2014.; zur Erstbeschreibung der genauen Funktionsweise dieses Mechanismus siehe Jinek et al. 2012.

77 Brouns et al. 2008.

78 Vgl. zur Funktionsaufklärung von Cas9 in Verbindung mit der CRISPR-RNA auch Deveau et al. 2007; Horvath et al. 2007; Marraffini/Sontheimer 2009.

79 Jinek et al. 2012. 


\section{Fazit - Experimentalsysteme, Black Boxes und Metaphern als Relais biopolitischer Dispositive}

Im Zuge der letzten zwei Abschnitte wurde versucht, einen historisch-genetischen Blick in die Black Box CRISPR-Cas9 zu werfen. Dabei wurden materielle, technische und diskursive bzw. metaphorische Bedingungen der Genese von CRISPR-Cas9 anhand von Schlaglichtern auf zwei zentrale Momente dieser Geschichte - die Stabilisierung erster Spuren und den epistemischen Sprung in den metaphorischen Raum des Krieges - herausgearbeitet.

Um zum Ende nun wieder auf die Ausgangsfrage zurückzukommen, wieso und wie sich ein molekularbiologisches Objekt wie CRISPR-Cas9 so bruchlos in Dispositive aktueller Biomacht einfügen lässt, sollen hier einige Aspekte der Experimentalsysteme, in denen sich CRISPR-Cas9 konstituiert, noch einmal hervorgehoben werden.

Der erste Aspekt, der sich schon im Zusammenhang mit den ersten Spuren von CRISPR abzeichnete, ist der, dass, bei aller prinzipiellen Offenheit und Unvorwegnehmbarkeit des Neuen in der molekularbiologischen Wissensproduktion, eben dieses Neue als Gefüge von Graphemen nur als spurförmiges Dispositiv überhaupt stabilisiert werden kann. Experimentalsysteme erzeugen also nicht einfach nur signifikante Differenzen, sondern „wissenschaftliche Objekte auf dem Weg zu technologischen Objekten“. ${ }^{80}$ Experimentalsysteme müssen also, sollen sie ihr eigenes Fortbestehen sichern, notwendig Black Boxes mit stabilen Input-Output-Relationen erzeugen. Sie funktionieren letztlich als Maschinen der Produktion des Neuen und als Maschinen der Konversion des Neuen in Erwartbares.

Zugleich weisen spurförmige Dispositive einen technischen Charakter auf, der sie prädestiniert, als Elemente biopolitischer Dispositive zu fungieren. Denn solche graphematischen Gefüge dienen, sobald sie kontrolliert darstellbar sind, immer schon dazu, weitere Grapheme erzeugen und stabilisieren zu können. Der Unabschließbarkeit der signifikanten Ketten, ihrer Verpflichtung auf die nächste Runde, wohnt damit ein entpersonalisierter, in die Experimentalanordnungen eingeschriebener „Wille zum Wissen“81 inne, der darauf zielt, Unverfügbares verfügbar, kontrollierbar und disponibel zu machen, widerständige in operative Materie zu überführen. Das Primat der Kontrolle des Lebendigen in den Experimentalsystemen, dass in die in ihnen erzeugten Objekte einfließt, erzeugt demnach Black Boxes, deren technischer Charakter darin besteht, Kontrollmaschinen des Lebendigen zu sein.

Zudem sind molekularbiologische Experimentalsysteme aufgrund der in ihnen zirkulierenden Metaphern privilegierte Relais des Austauschs zwischen der Sphäre des Politisch-Militärischen und des Biologischen. Im Zuge dieser fortdauernden Austauschprozesse sind nicht nur, wie Foucault einst schrieb, die „Massaker [...] vital

80 Rheinberger 1992, 71.

81 Foucault 1983 [1976]; Foucault 2012 [1971]. 
geworden“; ${ }^{82}$ umgekehrt sind, so sollte deutlich geworden sein, auch unsere Vorstellungen vom Lebendigen grundlegend vom Modell des Krieges in seiner je aktuellen Form geprägt. Vor diesem Hintergrund ist die Einstufung von CRISPR-Cas9 als Massenvernichtungswaffe genauso wenig einfacher Ausdruck der Angst vor Missbrauch einer an und für sich gesellschaftlich neutralen Technologie wie der molekularbiologische Rüstungswettlauf zwischen den USA und China Ausdruck bloßer Machtbeziehungen, sondern vielmehr immer auch die Explikation eines in den zirkulierenden Metaphern der Molekularbiologie längst angelegten und latent vorgehaltenen Möglichkeitsraums. In ganz ähnlicher Weise ist die technische Applikation des zur Black Box gewordenen CRISPR-Cas9 als Genome Editing-Technologie nurmehr der naheliegende nächste Schritt in einer langen Kette von Schritten, die CRISPR-Cas9 darauf vorbereitet haben, zu diesem molekularen Instrument par excellence der Biopolitik aufzusteigen, wenn dieses Objekt im Zuge seiner Konstitution als Black Box in den Diskursen der Molekularbiologie schon längst zu einer Waffe im molekularen Wettrüsten avanciert ist, die im seek and destroy-Modus ihre erkannten targets zerstört.

Wenn die historisch-genetische Öffnung der Black Box CRISPR-Cas9 - so selektiv und vorläufig sie in diesem kurzen Aufsatz auch vollzogen wurde, denn es wären noch viele weitere, wie etwa ökonomische, ethische, rechtliche etc. Bedingungsgefüge der Entstehung und Applikation von CRISPR-Cas9 zu berücksichtigen - dazu führt, die Methoden und Instrumente des Genome Editing und ihre Passförmigkeit in biopolitische Dispositive als Effekte solcher Dynamiken zu erkennen, die in viel umfassenderer Weise in unsere wissenschaftlichen Vorstellungen vom Lebendigen als einem Kriegsschauplatz und in die auf Verfügbarmachung und Kontrolle dieses Lebendigen durch experimentalsystemische Anordnungen der Labors der Life Sciences eingeschrieben sind, dann hätte ein solcher behutsamer erster Blick in die Black Box CRISPR-Cas9 schon viel bewirkt.

\section{Literaturverzeichnis}

Bachelard, Gaston (1988 [1934]), Der neue wissenschaftliche Geist, Frankfurt a. M. - ders. (1934), Le nouvel esprit scientifique, [ohne Ort].

Barrangou, Rodolphe (2014), „RNA events. Cas9 targeting and the CRISPR revolution“, in: Science 344 (6185), 707-708.

Brandt, Christina (2004), Metapher und Experiment. Von der Virusforschung zum genetischen Code, Göttingen.

Breakthrough Prize (2014), Recipients of the 2015 Breakthrough Prizes in Fundamental Physics and Life Sciences announced, https://breakthroughprize.org/News/21 (Stand: 20.9.2019).

Brouns, Stan J. J./Jore, Matthijs M./Lundgren, Magnus /Westra, Edze R./Slijkhuis, Rik J. H./Snijders, Ambrosius P. L./Dickman, Mark J./Makarova, Kira S./Koonin, Eugene V./van der Oost, John (2008), „Small CRISPR RNAs Guide Antiviral Defense in Prokaryotes“, in: Science 321 (5891), 960-964.

82 Foucault 1983 [1976], 163. 
Clapper, James R. (2016), Worldwide Threat Assessment of the US Intelligence Community, https:// www.dni.gov/files/documents/SASC_Unclassified_2016_ATA_SFR_FINAL.pdf (Stand: 20.9.2019).

Cyranoski, David (2016), „CRISPR gene-editing tested in a person for the first time“, in: Nature 539 (7630), 479.

Davies, Kevin/Mojica, Francisco (2018), „Crazy About CRISPR: An Interview with Francisco Mojica“, in: The CRISPR Journal 1 (1), 29-33.

Deutscher Ethikrat (2019), Eingriffe in die menschliche Keimbahn: Stellungnahme, https://www. ethikrat.org/fileadmin/Publikationen/Stellungnahmen/deutsch/stellungnahme-eingriffe-indie-menschliche-keimbahn.pdf (Stand: 20.9.2019).

Deveau, Hélène/Barrangou, Rodolphe/Garneau, Josiane E./Labonté, Jessica/Fremaux, Christophe/ Boyaval, Patrick/Romero, Dennis A./Horvath, Philippe/Moineau, Sylvain (2007), „Phage Response to CRISPR-Encoded Resistance in Streptococcus thermophilus“, in: Journal of Bacteriology 190 (4), 1390-1400.

Doudna, Jennifer A./Sternberg, Samuel H. (2017), A Crack in Creation: The New Power to Control Evolution, London.

Fleck, Ludwik (1993 [1935]), Entstehung und Entwicklung einer wissenschaftlichen Tatsache. Einführung in die Lehre vom Denkstil und Denkkollektiv (suhrkamp taschenbuch wissenschaft 31), Frankfurt a. M. [Basel].

Forterre, Patrick/Krupovic, Mart/Ishino, Yoshizumi (2018), „History of CRISPR-Cas from Encounter with a Mysterious Repeated Sequence to Genome Editing Technology“, Journal of Bacteriology 200 (7), 1-17.

Foucault, Michel (1983 [1976]), Der Wille zum Wissen: Sexualität und Wahrheit Bd.1 (suhrkamp taschenbuch wissenschaft 716), Frankfurt a. M. - ders. (1976), Histoire de la sexualité. Bd.1. La volonté de savoir, Paris.

Foucault, Michel (2012 [1971]), Die Ordnung des Diskurses, mit einem Essay von Ralf Konersmann, 12. Aufl., Frankfurt a. M. - ders. (1971), L'ordre du discours, Paris.

Goyal, M./Saunders, N. A./van Embden, J. D./Young, D. B./Shaw, R. J. (1997), „Differentiation of Mycobacterium tuberculosis isolates by spoligotyping and IS6110 restriction fragment length polymorphism“, Journal of Clinical Microbiology 35 (3), 647-651.

Gradmann, Christoph (2007), „Unsichtbare Feinde: Bakteriologie und politische Sprache im deutschen Kaiserreich“, in: Silvia Berger, Marianne Hänseler, Philipp Sarasin u. Miriam Spörri (Hgg.), Bakteriologie und Moderne: Studien zur Biopolitik des Unsichtbaren 1870-1920, Frankfurt a. M., 327-353.

Groenen, P. M./Bunschoten, A. E./van Soolingen, D./van Embden, J. D. (1993), „Nature of DNA polymorphism in the direct repeat cluster of Mycobacterium tuberculosis; application for strain differentiation by a novel typing method“", in: Molecular Microbiology 10 (5), 1057-1065.

Haraway, Donna J. (1991), Simians, Cyborgs and Women: The Reinvention of Nature, New York. Hardt, Annika (2019), Technikfolgenabschätzung des CRISPR/Cas-Systems: Über die Anwendung in der menschlichen Keimbahn, Berlin/Boston.

Helmreich, Stefan (2008), „Species of Biocapital“, in: Science as Culture 17 (4), 463-478. Horvath, Philippe/Romero, Dennis A./Coûté-Monvoisin, Anne-Claire/Richards, Melissa/Deveau, Hélène/Moineau, Sylvain/Boyaval, Patrick/Fremaux, Christophe/Barrangou, Rodolphe (2007), „Diversity, Activity, and Evolution of CRISPR Loci in Streptococcus thermophilus“, in: Journal of Bacteriology 190 (4), 1401-1412.

Ishino, Yoshizumi/Shinagawa, H./Makino, K./Amemura, M./Nakata, A. (1987), „Nucleotide sequence of the iap gene, responsible for alkaline phosphatase isozyme conversion in Escherichia coli, and identification of the gene product“, in: Journal of Bacteriology 169 (12), 5429-5433. 
Jansen, Ruud/van Embden, Jan D. A./Gaastra, Wim/Schouls, Leo M. (2002), „Identification of genes that are associated with DNA repeats in prokaryotes“, in: Molecular Microbiology 43 (6), 1565-1575.

Jinek, Martin/Chylinski, Krzysztof/Fonfara, Ines/Hauer, Michael/Doudna, Jennifer A./Charpentier, Emmanuelle (2012), „A programmable dual-RNA-guided DNA endonuclease in adaptive bacterial immunity“, in: Science 337 (6096), 816-821.

Jinek, Martin/East, Alexandra/Cheng, Aaron/Lin, Steven/Ma, Enbo/Doudna, Jennifer A. (2013), „RNA-programmed genome editing in human cells“, in: eLife 2013;2:e00471, https://doi. org/10.7554/eLife.00471 (Stand: 13.12.2019).

Kay, Lily E. (2005), Das Buch des Lebens: Wer schrieb den genetischen Code?, Frankfurt a. M. Kozubek, Jim (2016), Modern Prometheus: Editing the Human Genome with Crispr-Cas9, Cambridge. Latour, Bruno (1987), Science in Action. How to follow scientists and engineers through society, Cambridge.

Latour, Bruno (1988), The Pasteurization of France, Cambridge.

Latour, Bruno (1998 [1994]), „Über technische Vermittlung: Philosophie, Soziologie, Genealogie“, in: Werner Rammert (Hg.), Technik und Sozialtheorie, Frankfurt a. M., 29-81 - ders. (1994), „On Technical Mediation. Philosophy, Sociology, Genealogy“, in: Common Knowledge 3 (1), 29-64.

Latour, Bruno/Woolgar, Steve (1979), Laboratory Life. The Construction of Scientific Facts, Princeton.

Le Cong, F. A. Ran/Cox, David/Lin, Shuailiang/Barretto, Robert/Habib, Naomi/Hsu, Patrick D./ Wu, Xuebing/Jiang, Wenyan/Marraffini, Luciano A./Zhang, Feng (2013), „Multiplex genome engineering using CRISPR/Cas systems“, in: Science 339 (6121), 819-823.

Ledford, Heidi (2015), „CRISPR, the disruptor“, in: Nature 522 (7554), 20-24.

Maasen, Sabine/Mendelsohn, Everett/Weingart, Peter (Hgg.) (1995), Biology as society, society as biology: Metaphors, Dordrecht.

Mali, Prashant/Esvelt, Kevin M./Church, George M. (2013), „Cas9 as a versatile tool for engineering biology“, in: Nature Methods 10 (10), 957-963.

Marraffini, Luciano A./Sontheimer, Erik J. (2009), „Invasive DNA, chopped and in the CRISPR“, in: Structure 17 (6), 786-788.

Moebius, Stephan/Reckwitz, Andreas (Hgg.) (2008), Poststrukturalistische Sozialwissenschaften (suhrkamp taschenbuch wissenschaft 1869), Frankfurt a. M.

Mojica, F. J./Ferrer, C./Juez, G./Rodriguez-Valera, G. (1995), „Long stretches of short tandem repeats are present in the largest replicons of the Archaea Haloferax mediterranei and Haloferax volcanii and could be involved in replicon partitioning“, in: Molecular Microbiology 17 (1), 85-93.

Mojica, F. J./Juez, G./Rodríguez-Valera, F. (1993), „Transcription at different salinities of Haloferax mediterranei sequences adjacent to partially modified Pstl sites“, in: Molecular Microbio$\log 9$ (3), 613-621.

Mojica, F. J./Díez-Villaseñor, C./García-Martínez, J./Almendros, C. (2009), „Short motif sequences determine the targets of the prokaryotic CRISPR defence system“, in: Microbiology 155 (3), 733-740.

Müller-Wille, Staffan/Rheinberger, Hans-Jörg (2009a), Das Gen im Zeitalter der Postgenomik. Eine wissenschaftshistorische Bestandsaufnahme, Frankfurt a. M.

Müller-Wille, Staffan/Rheinberger, Hans-Jörg (2009b), Vererbung: Geschichte und Kultur eines biologischen Konzepts, Frankfurt a. M.

Nakata, A./Amemura, M./Makino, K. (1989), „Unusual nucleotide arrangement with repeated sequences in the Escherichia coli K-12 chromosome“, Journal of Bacteriology 171 (6), 3553-3556.

Nakata, A./Shinagawa, H./Amemura M. (1982), „Cloning of alkaline phosphatase isozyme gene (iap) of Escherichia coli“, Gene 19 (3), 313-319. 
National Academies of Sciences, Engineering, and Medicine; Policy and Global Affairs (2019), Second International Summit on Human Genome Editing: Continuing the Global Discussion, Washington (DC).

Nature 507 (7490), März 2014, Titelbild „Seek \& Destroy“, www.nature.com/nature/volumes/507/ issues/7490 (Stand: 23.9.2019).

Nelson, Fraser (2016), „The return of eugenics“, in: The Spectator, www.spectator.co.uk/2016/04/ the-return-of-eugenics (Stand: 23.9.2019).

Park, Alice (2016), „The Gene Machine. What the CRISPR experiments mean for humanity“, in: Time Magazine, time.com/4379535/in-the-latest-issue-75 (Stand: 23.9.2019).

Pontin, Jason (2015), „Editing Human DNA“, MIT Technology Review 118 (3), 2.

Pourcel, C./Salvignol, G./Vergnaud, G. (2005), „CRISPR elements in Yersinia pestis acquire new repeats by preferential uptake of bacteriophage DNA, and provide additional tools for evolutionary studies“, Microbiology 151 (3), 653-663.

Rammert, Werner (Hg.) (1998), Technik und Sozialtheorie, Frankfurt a. M.

Ranisch, Robert/ Müller, Albrecht M./Hübner, Christian/Knoepffler, Nikolaus (Hgg.) (2018), Genome editing - quo vadis? Ethische Fragen zur CRISPR/Cas-Technik, Würzburg.

Rheinberger, Hans-Jörg (1992), Experiment, Differenz, Schrift. Zur Geschichte epistemischer Dinge, Marburg.

Rheinberger, Hans-Jörg (2001), Experimentalsysteme und epistemische Dinge. Eine Geschichte der Proteinsynthese im Reagenzglas, Göttingen.

Rheinberger, Hans-Jörg (2005), Iterationen, Berlin.

Rheinberger, Hans-Jörg (2006), Epistemologie des Konkreten. Studien zur Geschichte der modernen Biologie (suhrkamp taschenbuch wissenschaft 1771), Frankfurt a. M.

Sarasin, Philipp (2003), Geschichtswissenschaft und Diskursanalyse (suhrkamp taschenbuch wissenschaft 1639), Frankfurt a. M.

Sarasin, Philipp/Berger, Silvia /Hänseler, Marianne/Spörri, Miriam (Hgg.) (2007), Bakteriologie und Moderne. Studien zur Biopolitik des Unsichtbaren 1870-1920 (suhrkamp taschenbuch wissenschaft 1807), Frankfurt a. M.

Schmidgen, Henning (2008), „Wissenschaft. Das Labor als Archiv und Maschine“, in: Stephan Moebius u. Andreas Reckwitz (Hgg.), Poststrukturalistische Sozialwissenschaften (suhrkamp taschenbuch wissenschaft 1869), Frankfurt a. M., 450-466.

Sherkow, Jacob S. (2015), „Law, history and lessons in the CRISPR patent conflict“, in: Nature Biotechnology 33 (3), 256-257.

Sherkow, Jacob S. (2017), „Patent protection for CRISPR: an ELSI review“, in: Journal of Law and the Biosciences 4 (3), 565-576.

Sherkow, Jacob S. (2018), „The CRISPR Patent Landscape: Past, Present, and Future“, in: The CRISPR Journal 1 (1), 5-9.

Šlesingerová, Eva (2019), „In risk we trust/Editing embryos and mirroring future risks and uncertainties“, in: Medicine, Health Care, and Philosophy 22 (2), 191-200.

Sommer, Marianne/Müller-Wille, Staffan/Reinhardt, Carsten (2017), in: Handbuch Wissenschaftsgeschichte, Stuttgart.

The Economist (2015), „Editing humanity“, in: The Economist, www.economist.com/leaders/2015/08/22/editing-humanity (Stand: 23.9.2019).

Wade, Nicholas (2015), „Scientists Seek Ban on Method of Editing the Human Genome“, in: The New York Times, www.nytimes.com/2015/03/20/science/biologists-call-for-halt-to-gene-editingtechnique-in-humans.html?_r=0 (Stand: 23.9.2019). 


\section{Bildnachweis}

Abb.1: Ishino, Yoshizumi/Shinagawa, H./Makino, K./Amemura, M./Nakata, A. (1987), „Nucleotide sequence of the iap gene, responsible for alkaline phosphatase isozyme conversion in Escherichia coli, and identification of the gene product“, Journal of Bacteriology 169 (12), 5432. 
